\title{
The Relationship Between the Origin of Higher Education and Social Development - A Study of Higher Education in Guangdong-Hong Kong-Macao Greater Bay Area
}

\author{
Zhang Ruixue \\ Education and Human Development, Universiti Pendidikan Sultan Idris, Tanjung Malim, Malaysia
}

\section{Email address:}

121503471@qq.com

\section{To cite this article:}

Zhang Ruixue. The Relationship Between the Origin of Higher Education and Social Development- A Study of Higher Education in Guangdong-Hong Kong-Macao Greater Bay Area. Education Journal. Vol. 10, No. 3, 2021, pp. 98-106. doi: 10.11648/j.edu.20211003.15

Received: May 20, 2021; Accepted: June 16, 2021; Published: June 21

\begin{abstract}
From the time when human beings entered the civilized society, fierce competition took place among people, between countries, in the political field, economic field, cultural field, population field and so on. No matter what form appeared, these competitions were realized based on higher education. As the leader of primary education, secondary education and vocational education, higher education plays the role of "fuel", "power" and "accelerator" in the modernization of any country. Higher education institutions have trained a large number of highly educated and high-quality talents, and these highly educated talents have become pioneers and leaders in the economic development of various countries and regions. At the same time, higher education promotes the construction of high-quality scientific research institutions, and researchers quickly transform scientific research achievements and effective patents into products and enter the market, thus promoting the global economic development. In this paper, the importance of higher education and its historical origin, which first appeared in the world, in the development of human society is thoroughly demonstrated, so as to prove the practical significance that the construction of Guangdong-Hong Kong-Macao Greater Bay Area in China must quickly form a higher education cluster.
\end{abstract}

Keywords: Human Development, The Historical Origin of Higher Education, Motive Force, Guangdong-Hong Kong-Macao Greater Bay Area, Greater Bay Area

\section{Introduction}

The object of higher education is human beings, and human beings are the teaching objects of higher education. Compared with basic education, higher education is no longer a simple means to teach people to make a living in society and some "rudimentary" common social knowledge [1]. For example, Professor William Conrad Rontgen, President of Würzburg University and Director of Institute of Physics, Germany, has been engaged in the research of cathode ray for a long time [2]. In his research of cathode ray in the late 19th century (November 8th, 1895), he applied the knowledge of advanced physics to discover that the high-speed moving electron current bombarded the anode target and produced electron transition. At the same time, a kind of ray is produced and released, which irradiates fluorescent substances and produces visible light. After repeated experiments, Professor William Conrad Rontgen thinks that this is no longer a cathode ray, and he is convinced that this is a new ray that has not yet been known, so he named it X-ray. Professor Alexander Fleming, who graduated from Wright Research Center, St. Mary's School of Medicine, University of London, is engaged in bacterial research. In the early 20th century (February 13th, 1928), he discovered in the laboratory that a substance can kill "Staphylococcus aureus". Subsequently, Professor Alexander Fleming continued to breed a lot of Penicillium in the culture solution, and then dropped the filtered culture solution into Staphylococcus aureus [3]. Within a few hours, "Staphylococcus aureus" all died. From then on, the great invention penicillin was born in the early 20th century. Penicillin was officially used in clinical medicine in early 1940s and 1941. Without Professor William Conrad Rontgen of Würzburg University and Professor Alexander Fleming of Wright Research Center of St. Mary's School of Medicine, University of London at that time, human beings discovered that X-ray and penicillin might be extended for a century or 
more.

To sum up, higher education has played a powerful booster role in the development of human society. With the continuous progress of science and technology and the continuous updating of higher education knowledge, the economic development of various countries and regions can not be separated from the strong support of higher education and scientific research institutes. At the same time, with a strong economic foundation as a guarantee, the scientific knowledge of various disciplines of higher education can be continuously updated, and the "unknown" science and technology in many fields such as physics, chemistry, mathematics, biology, etc., which have not yet been discovered by human beings, are inseparable from each other between higher education and national and regional economic development. For example, the per capita GDP of Shenzhen City in Guangdong-Hong Kong-Macao Greater Bay Area has reached 199,500 yuan in 2019. The 21st century is facing the rapid development of science and technology era, and the digitalization of electronic information has been applied and popularized in all walks of life. The new industrial restructuring has brought about an industrial revolution, and scientific and innovative enterprises need to be "locally" re-planned. In particular, high-tech industries have a "batch" demand for highly educated and high-quality talents trained by higher education institutions. Under the situation of human development and continuous social progress, the "intellectual development" of higher education has trained a large number of scientific and technological talents. More and more experts and scholars pay attention to the importance of higher education in the development of human society.

This paper will discuss the historical origin of higher education in some countries and its contribution to the world in the process of discussion, analyze the gap between higher education in western developed countries and developing countries in the process of discussion, and then discuss the practical significance that Guangdong-Hong Kong-Macao Greater Bay Area should quickly form a higher education cluster.

\section{Explore the Historical Origin of Higher Education}

\subsection{The University of Bologna in Italy Is the Earliest University in Europe Recorded in the Literature}

The word "universitas" first appeared in Europe, and modern people generally translate it into a university. In fact, the Latin word "universitas" has a very wide meaning in the 11th century, which mainly includes the following aspects: (1) People with common interests in philosophy "gathered together"; (2) More than one academic group "United"; (3) People with "good eloquence" were interested in astronomy and geography in the society at that time There is another explanation for the emergence of "universitas", because in the 11th century, the development of Christianity, whether it is numerous churches, a large number of Christian believers or the number of priests, has formed a considerable scale, and it is during this period that great differences have arisen in the relationship between people and churches within Christianity. The mainstream Christian school believes that people can communicate with God only through the church and clergy, so the church and clergy are authoritative. The non-mainstream Christian school believes that people can communicate with God according to their own beliefs, without the consent of the church and clergy. The church is just a Christian group "universitas", and the clergy is just a Christian who undertakes the work of the church "universitas" [4]. Based on the above differences, the non-mainstream schools of Christianity separated from Christianity and formed Protestantism, which is one of the three major schools of Christianity. During this period, Protestantism, Catholicism and Orthodox Church all set up their own church "universitas" to preach and preach. The place where these Christians "gather" to discuss philosophy and debate church rules, that is, the church is also called "universitas". These Protestants, Catholics and Orthodox Christians study civil law and religious regulations in "universitas". After graduation, their religious beliefs, This was the primary mode of higher education at that time.

Although the literature shows that higher education originated in ancient Egypt and China thousands of years ago, the "universitas" university in the true sense was established in western Europe from 11th to 12th century [5], and the University of Bologna in Italy was established in 1087 AD in 11th century. Bologna University is also called Bologna University (Italian: Almamater Studio Rum Università di Bologna, UNIBO). Bologna University can be traced back to a long time ago, and it is considered as the oldest university in the western world.

The history of Bologna University is intertwined with the great names of science and literature, which is the cornerstone and reference point of European culture [6]. Since the appearance of universitas in Italy, many famous people and outstanding students have been trained. At that time, many well-known priests and church members with good eloquence came to Bologna University in Italy to give lectures, in which they publicized their religious beliefs and Christian management methods, and vigorously promoted the role of civil law in stabilizing social order.

The reputation of the research center of Bologna University in Italy has spread all over Europe, and many British scholars have also come to Bologna to study. Perhaps the most famous one is Thomas Beckett. But in the following centuries, Bologna was visited by other outstanding scholars and students: Mirandola and Leon Batista Alberti, who studied the model method, and in 1506 Erasmus of Rotterdam, a nearly forty-year-old student, came here to study for one year. At the same time, Nicholas Copernicus (Polish mathematician and astronomer), as a member of Germanic nation, completed three years of study in Bologna. While studying the Pontifical law, he began his astronomical observation. In his book "The Revolution of the Celestial Balls", he remembered a special observation in Bologna on the evening of March 9, 1497. Again, paracel, AbrayChetdur, San Carlo borromeo, Torcuato 
Tasso, Carlo Godoni. Legend has it that a woman who taught in Bologna was between the 12th and 13th centuries, BetticiagoZadini. It is said that in order to attract a large number of people, her classes are not in the classroom, but in the public square. In the 15th century, the study of Greek and Hebrew began, and in the 16th century, the study of "natural magic"[7], experimental science. Philosopher Pietro pangbo Nazi insists on studying the laws of nature and opposes the traditional position of theology and philosophy. The representative figure of this period is UliseAldrovandi, whose contributions range from pharmacopoeia to the study of animals, fossils and natural wonders, and he collects and classifies them.

The 17th century was an important period for Bologna medicine and Malpigi, marcello. In 1660, he was called to Bologna as a lecturer in extraordinary medical theory and taught it to general medicine. The University of Bologna has been recruiting female teachers since the 12 th century. The opening to female scholars became obvious in the 18th century. The new ideas of the Enlightenment are changing the old prejudices, and women's culture is being debated all over Europe. Among the most famous female teachers, we may remember Laura Brazil: in 1732, she was awarded the position of professor of philosophy; In 1776, she was awarded the post of professor of experimental physics, teaching logic, metaphysics, philosophy, chemistry, hydraulics, mathematics, mechanics, algebra, geometry, ancient and modern languages.

In the 18th century, universities cultivated the development of science and technology. During this period, Luigi galvani, together with Alessandro Volta, Benjamin Franklin and Henry Cavendish, was one of the founders of modern electrician research.

With the emergence of the University of Bologna in Italy, the idea of running a school of Bologna University has swept the world like the wind. Influenced by Bologna University, 18 universities have appeared in Europe by AD 1300. By the end of the Middle Ages, some universities existed for a short time, but Paris University and Montpellier University, Bologna University and Padua University, Oxford University and Cambridge University, Vienna University and Prague University, Leipzig University [8] are still well-known universities with global influence on teaching quality.

\subsection{The Late Middle Ages Are Close to the Modern "Universitas" Because People Are Eager to Acquire More Natural Science Knowledge}

With the prosperity of cities in medieval Europe, more and more farmers bid farewell to their cultivated land and poured into cities. In this period, there was no large-scale machine manufacturing industry. In order to maintain their own lives and survival, these farmers joined the handicraft workshop-style manufacturing. Among them, many industries that maintain the normal operation of the city, such as processing wooden products, cotton textile, linen textile, ironware processing and manufacturing, clothing sewing, manpower transportation, animal power transportation, food processing, wine making, housing construction, etc., have appeared in large numbers, which also gave birth to the development of urban economy and the expanding number of new citizens, which has brought many social problems, such as: "craftsmen" and "guilds" in various industries maximize their own interests. Began to engage in malicious commercial competition with other craftsmen and guilds in other regions. During the heyday of malicious competition, craftsmen and guilds will use the most primitive rough way to fight with each other to achieve the purpose of monopoly. In fighting with each other, even "craftsmen" will suffer personal injury, which seriously affects and destroys the city's economic order and security and stability.

In order to stop these craftsmen's malicious commercial competition and meet the needs of the times and society, a "merchant Federation" organization similar to modern society appeared. In the long-term social practice, the members of these chambers of commerce found that due to the serious lack of knowledge of natural science, which led to the fact that the productivity of the industry was backward and the work efficiency was low. Of course, the "Merchants Federation" realized the seriousness of this problem, so the well-funded "Merchants Federation" set up its own chamber of commerce school in the form of "universitas", and the commercial guild set up a new educational institution to meet the educational needs of the new citizens. It is not the name of a school, it is the general name of a school for all children in the citizen class. It contains a variety of schools of different types and sizes, such as guild schools run by handicraft associations and Chirt schools set up by merchants' associations [9]. The entrance threshold of this kind of chamber of commerce school is very low, as long as people over the age of 14 can apply for admission. With the continuous development of urban economy and the increasing population of ordinary citizens in Europe, those who are eager to obtain more natural science knowledge can apply for admission without any cultural and educational foundation, for example; In order to improve their professional skills, street magicians who set up stalls to sell art are more willing to join "universitas" and get more "magic" under the guidance of famous school teachers, and craftsmen who work as "carpenters" in the wood processing industry have a persistent love for housing construction and have joined "universitas" one after another. Here, craftsmen laid the foundation for the future engineer career. In order to improve the working efficiency of looms, craftsmen who work in the textile industry rush to make various structural changes on the existing looms in order to reduce the friction force when weaving machines are pulled to the minimum. The purpose of doing this is to reduce the labor intensity of people at work, and the other purpose is to prolong the service life of looms. In order to invent more advanced looms, these craftsmen have also joined the "universitas" study. You can apply for admission as long as you are at least 14 years old, and the average person must study at universitas for at least 3 years after entering school.

In the 12 th to 15 th centuries, with the development of urban economy, social progress and the increasing strength of the new citizen class in Europe, new educational institutions and 
forms close to the modern times began to appear [10]. At this time, the funds for running schools did not need to be obtained from churches, but came from the tuition fees paid by students and the sponsorship of business associations, and the funds donated by enterprises that gained benefits in running schools to buy teaching equipment, pay the remuneration for hiring university staff, and repair the school buildings and maintain the school. Principals and teachers are jointly appointed by guilds and municipal authorities [11].

In the early 11th century, the school-running style of Bologna University in Italy is a teaching mode centered on students' autonomy. During the teaching process, students ask each other questions, argue with each other, and get answers in the debate. At the same time, lecturers should also understand the problems that students are interested in in in order to give students a deeper interpretation and guidance. If students are dissatisfied with teachers or principals, they can be dismissed from their work contracts through trade chambers. Such a school-running mode has existed for a long historical period. This mode of running a school centered on student autonomy also affects all European countries. Newly established universities in European countries except Italy have followed this mode of running a school centered on student autonomy, which has been consolidated and improved in a considerable historical period. If we study the historical reasons for this teaching mode centered on student autonomy, we will find that all universitas were organized by churches in the social background of the 11th century at that time, and the students studying in universitas were Christians, who had the authority to challenge them in monasteries and bishops' universities. Since the educational institutions only have monasteries and bishops' university halls as forms of higher education, the students (Christians) of "universitas" naturally have the authority of student (Christians) autonomy, which comes from the spirit of contract between churches and Christians. This teaching mode centered on student autonomy lasted until the 13 th century.

From the 11 th century to the 13 th century, "universitas" is a school focusing on European Medieval philosophy. Its teaching contents are mainly teaching theology, religion, social economy, folk law and social etiquette. Students who study these courses are taught that all social problems and social phenomena can be controlled and solved by people. European medieval philosophy doesn't recognize any natural scientific phenomena that exist objectively in the material world but haven't been discovered by human beings, and doesn't take the initiative to study such natural sounds, sunshine, thunder and lightning. From the 11th century to the 13th century, "universitas" is a school focusing on European Medieval philosophy. Its teaching contents are mainly teaching theology, religion, social economy, folk law and social etiquette. Students who study these courses are taught that all social problems and social phenomena can be controlled and solved by people. European medieval philosophy doesn't recognize any natural scientific phenomena that exist objectively in the material world but haven't been discovered by human beings, and doesn't take the initiative to study such natural sounds, sunshine, thunder and lightning.

Italian astronomer ZekodaScoori discovered and demonstrated in 1327 that "the earth is spherical, and there are human beings in the other hemisphere", but he was burned alive by the church. The "crime" of ZekodaScoori is to violate the teachings of the Bible. Italian astronomer ZekodaScoori discovered and demonstrated in 1327 that "the earth is spherical, and there are human beings in the other hemisphere", but he was burned alive by the church. The "crime" of ZekodaScoori is to violate the teachings of the Bible [12]. Professors of monasteries and bishops' universities instill in students the belief that everything in society is brought to us by "God", and other philosophies are heresy. Take medicine as an example: Servit (1511 1553), Spanish doctor, natural scientist in Renaissance, discoverer of pulmonary circulation. In 1553, he secretly published the book "Revival of Christianity" [13], which expounded his views on pulmonary circulation from the viewpoint of monism. His book was regarded as heresy by Catholics and Christians, and he was wanted by the inquisition. Christianity holds that human life, aging, disease and death are all arranged by God, and refuses to admit that medicine can control human life, aging, disease and death.

Before the 13th century, natural sciences, especially some practical sciences, were not recognized by the Christian Church. For example, geography, meteorology, law, human anatomy, physiology, pathology, astronomy, physics and art were regarded as heresy by the church, so people who pursue the above natural sciences and practical sciences have no legal and fixed "universitas". However, after the 13th century, these students began to wander around Europe looking for people who share their beliefs and ideas, and also looking for teachers who can continue to teach their knowledge. These students gathered in "universitas", and the students collectively paid for hiring teachers to teach for themselves. Of course, there is no uniform standard and requirement for students to pay for their own teachers. The solution is usually to discuss the amount of funds undertaken by students. Although there will be disputes in the process of discussing the amount of funds undertaken by each student, the students can always reach a common understanding under the coordination of the "Student Autonomy Association". In view of the above-mentioned "teaching market" phenomenon, teachers who publicize and teach natural sciences all over Europe are also looking for areas where students gather very much, and are close to the student gathering places. Teachers who teach natural science should first get the students' approval after finding "universitas" where students gather, and students and teachers should sign a cooperation agreement together:(1) The main content of the agreement is the amount of funds for students to support teachers; (2) Under what circumstances can the agreement be continued and terminated;(3) Teachers should give lectures immediately when the bell rings in class, and finish the course on time when the bell rings after class.

In "universitas", because students are on the side of paying money when signing the agreement to hire teachers, students 
have mastered the initiative of university autonomy [14]. When the road of higher education came to the 13th century, it began to present the elementary teaching mode of modern universities, which laid a good foundation for the regularization of universitas after the 17 th century.

Students studying in Europe can send an official letter to the government of the city where universitas is located in the name of "Student Autonomy Federation", get special permission from the government, and legally rent a house as a school for universitas students to attend classes and a dormitory for students to live in. Students can also enjoy other special rights and treatment in the city. Students studying in Europe can send an official letter to the government of the city where universitas is located in the name of "Student Autonomy Federation", get special permission from the government, and legally rent a house as a school for universitas students to attend classes and a dormitory for students to live in. Students can also enjoy other special rights and treatment in the city.

\section{The Importance of Higher Education in the Development of Human Society}

\subsection{Innovation and Progress in the Field of Natural Science are Inseparable from Higher Education}

In the continuous changes of modern society and the rapid and orderly operation of economic development, the promotion and support of higher education are inseparable. Higher education plays the role of "fuel", "power" and "accelerator" in all previous industrial revolutions and industrial structure transformation. Higher education is a very important link in the process of "integration of production and scientific research". In today's manufacturing industry, which is represented by low efficiency and labor intensive, is transforming to high efficiency digitalization and information automation, research institutes of higher education have made great contributions to the transformation of industrial structure.

Take the relationship between higher education resources and local economic development in new york Bay Metropolitan Area as an example: to demonstrate the direct relationship between talents with higher education and local economic development, there are 7 Ivy League schools in new york Bay Area, namely Columbia University, Cornell University, Princeton University, Harvard University, Yale University, Brown University and University of Pennsylvania [15]. By 2020, according to the data released by the official statistics bureau, there were 270 Nobel laureates in the above 7 Ivy League schools Among the 2153 members of Forbes Global Billionaires List in 2019, new york once again topped the list with 84 billionaires [16], Among them, 62 billionaires graduated from Harvard University. Famous billionaires include Michael Bloomberg, mayor of new york, Kenneth Griffin, founder of Castle Investment Group and hedge fund tycoon, and Rockefeller, an oil tycoon [17]. They all graduated from Harvard University. According to the statistics of the U.S. Census Bureau, in 2015, about 37.54\% of the residents over 25 years old in New York Bay Metropolitan Area had bachelor degree or above, of which about 2,122,800 had master degree or above. Graduates from these world-famous universities work in high-tech industries in New York Bay Area, which directly drive the total GDP of New York Bay Metropolitan Area. According to the data of the US Bureau of Economic Analysis, the total GDP of New York Bay Metropolitan Area in 2015 was 1.6 trillion US dollars [18], accounting for $9.89 \%$ of the total GDP of the United States.

Take the relationship between higher education resources and local economic development in Tokyo Bay Area as an example: According to the data released by the Ministry of Education, Culture, Sports, Science and Technology of Japan in 2015, there are 225 higher education schools in Tokyo Bay Area, accounting for $29 \%$ of the total number of higher education schools in Japan. Tokyo is Japan's higher education center, cultural center and political center. One third of all Japanese higher education schools are located in Tokyo, and the famous Tsukuba University is located at the foot of Tsukuba Mountain in Ibaraki Prefecture, northeast of Tokyo. The teaching organization forms of Tsukuba University are obviously different from those of ordinary universities. Tsukuba University does not have the $\mathrm{X}$ department and $\mathrm{X}$ discipline system of Japanese ordinary universities, but establishes a new teaching organization classification of teaching groups, $\mathrm{X}$ subjects and specializing in a certain $\mathrm{X}$ field. Japanese Hideki Yukawa won the Nobel Prize for the first time in 1949 [19]. Up to 2018, 26 Japanese have won Nobel Prize, and the number of winners is second only to Europe and the United States.

\subsection{The Late Start of Chinese Modern Higher Education Is Directly Related to the Backwardness of Higher Education}

The historical reason why China's Guangdong-Hong Kong-Macao Greater Bay Area higher education lags behind Europe, the United States and other countries is directly related to the late start of China's modern higher education itself. The earliest "universitas" recorded in Chinese literature appeared in the form of academies and schools. For example, Yuelu Academy, founded in $976 \mathrm{AD}$, experienced the Southern Song Dynasty, Yuan Dynasty, Ming Dynasty and Qing Dynasty, and merged with Hunan Provincial University Hall in 1903, and was transformed into Hunan Higher School [20]. There are Beiyang University Hall, which was founded in 1895 during the Qing Dynasty in China, and Nanyang Public School in 1896. However, the so-called "higher education" mentioned above does not have the organization and structure of modern universities, and these "universitas" do not set up majors, disciplines and directions. Students who graduated from "universitas" have no clear employment direction. The above universitas do not have all the characteristics of modern universities, so they are not really universities.

China was in a semi-feudal society and a semi-colonial state 
from 1911 to 1949 AD, with slow economic development, extremely low average GDP of people, and difficulty in maintaining people's daily life. The state finance is empty, and there is no fund to support all university funds for higher education with modern characteristics. In addition, at the beginning of the 20th century, warlords fought against the people, and in order to maintain the status and stability of the ruling class, the government at that time adopted the policy of ignorance of the people in the development of higher education, and was unwilling to let the people accept too much cultural and scientific knowledge, and the educational information was in a closed state. They are worried that people will confront the government after mastering scientific knowledge. This phenomenon lasted until 1949 when New China was founded. Unfortunately, a wrong political movement happened from 1966 to 1976, which was called the Great Proletarian Cultural Revolution. This movement led to the suspension of classes in all colleges and universities, and stopped recruiting new students. At that first national educational work conference held in 1971, the gang of four concoct the so-called "two estimates", that is, the "revisionist line" implement by the front of science and technology education in the seventeen years before the "cultural revolution". most of the intellectuals' "world outlook is basically bourgeois" and are "bourgeois intellectuals" [21], Experts, professors and scholars in institutions of higher learning are called "reactionary academic authorities of the bourgeoisie". These experts, professors and scholars went to the countryside to receive farmers' education, which caused the basic paralysis of higher education. In July 1977, the Third Plenary Session of the Tenth CPC Central Committee decided to reinstate Comrade Deng Xiaoping, a great man of the century, as Vice Premier of the State Council. Focus on science and education. In the view of Deng Xiaoping, a great man in the century, science and education work is the key to realize the four modernizations, while the enrollment of higher education is linked with the work of higher education and universal education, as well as education, all walks of life and thousands of families. Therefore, this work has also become a "breakthrough" for the rectification of educational work after his return to work. Finally, in 1977 AD, the enrollment work of higher education institutions was resumed. From then on, China's higher education can be said to have entered a new period of vigorous development of higher education. Focus on science and education. In the view of Deng Xiaoping, a great man in the century, science and education work is the key to realize the four modernizations, while the enrollment of higher education is linked with the work of higher education and universal education, as well as education, all walks of life and thousands of families. Therefore, this work has also become a "breakthrough" for the rectification of educational work after his return to work. Finally, in 1977 AD, the enrollment work of higher education institutions was resumed. From then on, China's higher education can be said to have entered a new period of vigorous development of higher education.

\section{Re-discuss the Practical Significance that Guangdong-Hong Kong-Macao Greater Bay Area Should Quickly form a Higher Education Cluster}

\subsection{The Current Situation of Higher Education Resources in Guangdong-Hong Kong-Macao Greater Bay Area, China}

Although there is a big gap between Guangdong-Hong Kong-Macao Greater Bay Area's higher education resources and those of Europe, the United States and Japan, compared with Beijing, where China's higher education is the strongest, there is also a huge gap in education quality and teaching level.

There are 26 universities listed in the 211 Project and 8 universities listed in the 985 Project in Beijing, including Peking University, Renmin University of China, Tsinghua University, Beijing University of Aeronautics and Astronautics, Beijing Institute of Technology, China Agricultural University, Beijing Normal University and Central University for Nationalities [22]. However, there are only 4 universities listed in the 211 Project in Guangdong-Hong Kong-Macao Greater Bay Area, and the number of universities listed in the 985 Project is even smaller. Only 2 universities (excluding the Hong Kong SAR and Macao SAR) are Sun Yat-sen University and South China University of Technology.

From the above data of higher education comparison between Beijing and Guangdong-Hong Kong-Macao Greater Bay Area, it is an indisputable fact that there is a gap between Guangdong-Hong Kong-Macao Greater Bay Area and countries with developed higher education in the world or cities with developed higher education in China. From the current number of higher education institutions, the foundation of higher education resources is still rather unstable, and there is no cluster structure of higher education in Guangdong-Hong Kong-Macao Greater Bay Area. Can't achieve the guarantee function of supporting Guangdong-Hong Kong-Macao Greater Bay Area's economic development. According to the development history of higher education in the other three Bay Areas (new york Bay Area, San Francisco Bay Area and Tokyo Bay Area), this paper draws a conclusion that if higher education is to develop comprehensively, deeply and at a high level, it must be clustered by a large number of higher education institutions. Therefore, if Guangdong-Hong Kong-Macao Greater Bay Area wants to improve the speed and level of economic development (GDP), it must be supported and guaranteed by Guangdong-Hong Kong-Macao Greater Bay Area's higher education cluster, so that it can be truly realized. Guangdong-Hong Kong-Macao Greater Bay Area is composed of Hong Kong, Macau, Guangzhou, Shenzhen, Zhuhai, Foshan, Huizhou, Dongguan, Zhongshan, Jiangmen and Zhaoqing [23]. Its higher education. The distribution of resources is extremely uneven, please refer to the following 
chart data.

Table 1. Distribution map of all universities (Excluding the three-year system) in Guangdong-Hong Kong-Macao Greater Bay Area.

\begin{tabular}{lll}
\hline Guangzhou & university & 37. \\
Shenzhen & university & 5. \\
Zhuhai & university & 4. \\
Foshan & university & 2. \\
Huizhou & university & 1. \\
Dongguan & university & 3. \\
Zhongshan & university & 1. \\
Jiang men & university & 1. \\
Zhaoqing & university & 3. \\
Hong Kong & university & 18. \\
Macao & university & 6. \\
\hline
\end{tabular}

It can be clearly seen from the above chart that universities at the undergraduate level are concentrated in the Hong Kong Special Administrative Region and Guangzhou, while the higher education resources in Shenzhen, Zhuhai, Foshan, Huizhou, Dongguan, Zhongshan, Jiangmen, Zhaoqing and Macao are rather weak. In addition, large-scale scientific and technological innovation bases are all concentrated in Hong Kong, Guangzhou and Shenzhen. This unbalanced distribution cannot form an effective higher education cluster and high-quality operation of scientific and technological development industries. If an effective higher education cluster cannot be formed in Guangdong-Hong Kong-Macao Greater Bay Area, it will be very unfavorable to the sustainable development of science and technology and innovation industries, and also unfavorable to the research and promotion of digital products in information industry. In view of the unbalanced distribution of higher education resources in Greater Bay Area, we conducted a social survey, and found that the higher education resources in any region or city are directly related to the local fiscal revenue and the level of economic development (GDP). In terms of capital investment and use of higher education, there is no system and method of communication between nine cities and two special administrative regions in Guangdong-Hong Kong-Macao Greater Bay Area. The repeated purchase rate of teaching instruments and research equipment purchased by higher education institutions in each city is too high, and the research overlap rate of research projects is too high. There are a large number of courses with low gold content and courses that obviously can not keep up with the pace of the times are still being offered in schools, which leads to the phenomenon that students are tired of classes and skip classes.

If we want to build an effective higher education cluster, it is definitely not a simple sum of all schools or a combination of numbers, but rather higher education schools, scientific research institutions and experimental bases in the higher education cluster should give full play to their own proficient research directions and professional leading specialties to avoid overlapping with other schools.

For example; Higher education institutions and research institutes in Hong Kong Special Administrative Region research and develop digital technology and digital products earlier than other regions, and are always in a leading position in digital technology and digital products. Due to geographical and historical relations, Hong Kong has a large number of scientific research teams and experts from all regions of the world, so it should focus on research and development of digital technologies and products. Shenzhen has gained quite high social recognition for its early research and development of biological agents and unmanned intelligent technology.

For example: Shenzhen Institute of Immunogene Therapy, Binde Biology, Zhenmai Biology, Heyikang, Yuanzhengcells, Beike Biology, PurikinBiology, Yuanxing Gene and other enterprises have considerable popularity. In response to the new coronavirus epidemic in the world, Zhenmai Bio developed two new crown detection reagent products at the beginning of the epidemic, namely novel coronavirus nucleic acid detection kit (fluorescence PCR method) and novel coronavirus nucleic acid detection kit (single molecule fluorescence sequencing method) [24]. Another example: Shenzhen has the world-famous Shenzhen DJI Innovation Technology Co., Ltd., which accounts for $70 \%$ of the global drone market among Shenzhen drone companies, including DJI [25]. There are more than 300 enterprises such as zero-degree intelligent aircraft, AEE Shenzhen Yidian Technology, Habersen Technology, corbett and Territory Intelligence, so Shenzhen should focus on research and development of biological agents and unmanned intelligent equipment.

We suggest that to establish an effective higher education cluster, there must be intervention and guidance from the national level, and a coordinating body for the use, distribution and scheduling of all funds related to higher education resources should be set up, whose responsibility is to solve the unbalanced distribution of higher education resources in Guangdong-Hong Kong-Macao Greater Bay Area and to uniformly lay out the research directions of scientific research, development, science and technology and innovation projects of higher education clusters in various cities. Under the action of higher education cluster, education, scientific research and integration are formed, which promotes the development of high-tech and innovative industries, and can quickly transform scientific research achievements into products and enter the market circulation field. At present, high-tech innovation industry and information industry urgently need the support and intervention of higher education cluster [26].

\subsection{At Present, Guangdong-Hong Kong-Macao Greater Bay Area's Higher Education Resources Must Be Diversified and Shared to Achieve the Rapid Development of Other Education Clusters}

The causes of resource sharing have been discussed in detail in the second half of 3.1 of this article. Here are some typical models of higher education resource sharing that need to be solved urgently:

With the rail transit between cities in Guangdong-Hong Kong-Macao Greater Bay Area, the diversity of intercity trains, electric motor trains, high-speed railway trains and expressways has appeared, which has further shortened the travel time between the two cities. For example, it takes only 
15 minutes to get to Hong Kong Kowloon West Railway Station by bus from Shenzhen Futian Railway Station, and it takes about 30 minutes to get to Huizhou South Railway Station by bus from Guangzhou No. 22 underground railway train via Dongguan, thus truly realizing rail transit across cities. The exchanges between different cities are becoming more and more convenient, and the time is getting shorter and shorter. It can become a reality to establish a system of selecting courses for students across schools and regions among universities. Students can choose different inter-city university courses according to their own wishes and favorite public basic courses and professional basic courses. The course achievements and "grade points" obtained by these students during the course selection should be mutually recognized by the two universities. This will not only solve the problem of shortage and shortage of curriculum resources in individual universities, but also put an end to the phenomenon of waste and low effective utilization rate of curriculum resources in individual universities, and will also help mobilize the enthusiasm of Guangdong-Hong Kong-Macao Greater Bay Area university students for "free course selection".

Large-scale test equipment and instruments in laboratories and research institutes of higher education account for the largest proportion of the single investment and expenditure of the school. It often happens that the idle time of test equipment and instruments is too long after the experiment of a certain project is finished and before the new experimental project comes, and the idle rate of test equipment and instruments is too high. However, other universities cannot successfully carry out experiments of the same project because they do not have such test equipment and instruments, which seriously affects the social and economic benefits of laboratories of various universities. In order to solve this problem, we should put the resource sharing of large-scale experimental equipment and instruments in universities on the agenda. First of all, it is necessary to establish an information sharing system for large-scale test equipment and instruments, and let universities know the specifications, functions and technical parameters of large-scale test equipment and instruments owned by other universities in Guangdong-Hong Kong-Macao Greater Bay Area, so that schools can choose whether to share resources. It is also necessary to establish a fund settlement system for lenders and users of "resource sharing" among universities, which not only mobilizes the enthusiasm of lenders, but also solves the historical problem of unbalanced distribution of large-scale test equipment and instruments in Guangdong-Hong Kong-Macao Greater Bay Area. More importantly, it can also promote the cooperation between universities and the exchange of academic and scientific research.

Some universities still have a wrong understanding of whether their educational resources should be public and open to the outside world, and some universities are not aware of the sharing of higher education resources. The reason for this is the backward thought of "resource protection" on the educational resources of our school. In reality, there are still many problems in sharing educational resources that need to be solved urgently. There are not only two aspects mentioned above, such as "curriculum sharing" and "sharing of large-scale experimental equipment and instruments", such as opening and sharing of teaching resources, opening and sharing of teachers' resources, personnel training and sharing of scientific research. Because of the length of the article, it is not listed in detail here.

\section{Conclusion}

This paper quotes the latest data to explain the historical origin of the earliest appearance of higher education, the importance of the development of human society, and the current situation of higher education clusters in Guangdong-Hong Kong-Macao Greater Bay Area, China. The purpose of this paper is to respond to the decision of the CPC Central Committee and the State Council on building a highland of education and talents mentioned in the Outline of Guangdong-Hong Kong-Macao Greater Bay Area Development Plan. The guiding ideology of this paper is to clearly understand the current situation and existing problems of higher education clusters in Guangdong-Hong Kong-Macao Greater Bay Area, and to discuss how to speed up the construction and development of higher education clusters through experts, professors and scholars from universities in Guangdong-Hong Kong-Macao Greater Bay Area, and to use existing higher education resources to speed up the construction of international education demonstration zones in Guangdong-Hong Kong-Macao Greater Bay Area. In educational practice, it should be in line with world-class universities, and learn from the experience of international first-class discipline construction in the process of discipline construction [27]. The cultures of 9 cities and 2 districts in Guangdong, Hong Kong and Macao have their commonness and similar humanistic thoughts. The barrier-free language exchange in Guangdong, Hong Kong and Macao, especially the important index (GDP) of Guangdong-Hong Kong-Macao Greater Bay Area's economic development, has been ranked among the top in the country, which is an important guarantee for speeding up the construction of higher education clusters in Guangdong-Hong Kong-Macao Greater Bay Area, China.

\section{References}

[1] Guo Jianbin. On the responsibility of higher education in society [D]. Shanxi: Shanxi University, 2017: 7.

[2] Ji Run Time. In what year was X-ray invented? [EB/OL]. (2017-11-27) [2021-05, 19]. https://zhidao.baidu.com/question/1512128153627883860.html.

[3] Chen Dongfang, Zheng Yuqiao. The miracle of saving billions of human beings with penicillin [J]. Medical World, 2008 (11): 50-53.

[4] Zhang Kang. Elegant Taste and Secular Life in Dutch Seventeenth Century Painting [D]. Jiangsu: Nanjing University of the Arts, 2019: 17. 
[5] Nanxi 687955. How many years are European universities earlier than Chinese ones?[EB/OL]. (2020-10-15) [2021-05, 19].

https://zhidao.baidu.com/question/1645940915768370900.htm 1.

[6] Shirley senior. European study brochure - university of bologna in Italy [EB/OL]. (2020-10-19) [2021-05, 19]. https://zhuanlan.zhihu.com/p/266259916.

[7] Anon. Western European medieval universities produce [EB/OL]. (2008-12-02) [2021-05, 19]. https://doc.xuehai.net/b5d49ad24f185c65989d47424.html.

[8] Li Xiaoying. Viewing the Evolution of Higher Education Attribute from the Change of University Appellation [J]. Journal of Guangxi Normal University (Philosophy and Social Sciences Edition), 2008 (03): 104-107.

[9] Hou Mengmeng. An Analysis of the Relationship between the Mottos of Western Universities and Cultural Trend of Thought [J]. Cultural and Educational Data, 2014 (18): 53-54.

[10] Zhu Dequan, Yi Lianyun. Introduction to Pedagogy [M]. Southwest Normal University Press, 2003.

[11] Wangjie. Xia Youjian. Cao Chuanlong. Medieval European University [EB/OL]. (2015-12 -- 05) [2021-05 http://www.doc88.com/p-7038944603918.html.

[12] Hexi. The Clash of Civilizations: The Historical Roots of Terrorism [J]. Xinmin Weekly, 2015, 000 (045): 46-50.

[13] Zhang Limin. Using biology history teaching to strengthen students' quality education [J]. Heilongjiang Medical Science, 2008 (04): 43-44.

[14] Baidu net friend 66 c3698fc. History of Chinese university community [EB/OL]. (2016-12-01) [2021-05, 19]. https://zhidao.baidu.com/question/180314733.html.

[15] Yang Liuqun. Research on student affairs management of American Ivy League universities [D]. Hunan: Hunan Normal University, 2019: 32.

[16] Jiang Mengna. Top 10 cities with the most billionaires in the world: China has four! [EB/OL]. (12), 2019-03 - [2021-05, 19]. http://wap.ycwb.com/2019-03/12/content 30217177.htm.
[17] Anon. The cradle of billionaires [J]. Entrepreneur information, 2010 (10): 127.

[18] Tao Feng, Tang Yitian. Cultivation of world Bay Area [N]. Beijing business daily, 2019-02-19.

[19] Su Nan, Chen Zhi, Wang Hongguang. The Enlightenment and Reference of "Japan's Nobel Prize Program" -- A Comparative Perspective between China and Japan [J]. Global Science \& Technology Economics Review, 2018, 33 (10): 61-70.

[20] Jiang Huai. Yuelu Academy: Ancient Academic Temple [J]. Archives and Time, 2004 (10): 43-44.

[21] Fan Guoliang. Research on the Development and Evolution of School Physical Education Thought in China since Reform and Opening-up [D]. Guangdong: South China Normal University, 2003.

[22] Yang Minzhi. Research on the Design and Utilization of Teaching Space in New Teaching Building in Beijing [D]. Beijing: North China University of Technology, 2013.

[23] Zhou Tianjing. Reflections on the construction path of universities integrating into the Guangdong-Hong Kong-Macao Greater Bay Area [J]. Jiangnan Forum, 2019 (008): 43-44.

[24] Shenzhen Zhenmai Biotechnology Co., Ltd. Zhenmai biological was selected into the development and industrialization support plan of Xinguan detection reagent of Shenzhen Development and Reform Commission [EB/OL]. (2020-06-17) [2021-05-19]. $\mathrm{http}: / /$ www.genemind.com/news view.aspx?nid=2\&typeid=4 \&id $=556$.

[25] Ma Yihua, GuoYifu. Successful experience and inspiration of DJI UAV to occupy the international market $[\mathrm{J}]$. Practice of Foreign Trade and Economic Cooperation, 2016 (001): 76-79.

[26] LU Qiaoqiao, Lao Hansheng. International comparison and role orientation analysis of higher education in the Guangdong-Hong Kong-Macao Greater Bay Area [J]. Education Exploration, 2018 (006): 54-59.

[27] ZuoZelin. The value and strategy of education cooperation development in the Guangdong-Hong Kong-Macao Greater Bay Area [J]. Journal of South China Normal University (Social Science Edition), 2020 (2). 